\section{How the circumcision solution in Africa will increase HIV infections}

\author{
Robert S. Van Howe, Michelle R. Storms \\ Department of Pediatrics and Human \\ Development, College of Human \\ Medicine, Michigan State University, \\ Marquette, MI, USA
}

\begin{abstract}
The World Health Organization and UNAIDS have supported circumcision as a preventive for HIV infections in regions with high rates of heterosexually transmitted HIV; however, the circumcision solution has several fundamental flaws that undermine its potential for success. This article explores, in detail, the data on which this recommendation is based, the difficulty in translating results from high risk adults in a research setting to the general public, the impact of risk compensation, and how circumcision compares to existing alternatives. Based on our analysis it is concluded that the circumcision solution is a wasteful distraction that takes resources away from more effective, less expensive, less invasive alternatives. By diverting attention away from more effective interventions, circumcision programs will likely increase the number of HIV infections.
\end{abstract}

\section{Introduction}

At the XVIII International AIDS conference held in Vienna, there was a strong push to gather funding to circumcise 38 million men in sub-Saharan Africa within the next five years. The belief is that male circumcision provides the best hope of decreasing the spread of HIV infection there. We believe these efforts are misguided.

Although the World Health Organization (WHO) and UNAIDS have supported circumcision as an HIV preventive in regions with high rates of heterosexually transmitted HIV, the circumcision solution has several fundamental flaws that have been glossed over by its proponents within these organizations. These proponents, who have been touting the "benefits" of circumcision for decades, have developed plans to circumcise Africa on behalf of WHO and UNAIDS. ${ }^{1}$ If their goal is to prevent the spread of HIV in Africa, circumcision will only serve to divert resources away from effective measures.

In this paper, we will expose the lack of sci- entific evidence, biological plausibility, and epidemiological evidence that provides the foundation for the circumcision solution. We will demonstrate how circumcision will likely increase the number of heterosexually transmitted HIV infections. Finally, we will discuss how poorly circumcision compares with other interventions.

\section{Lack of scientific evidence}

The results of three randomized clinical trials (RCTs) are often presented as proof beyond a reasonable doubt that male circumcision prevents HIV infection. ${ }^{2}$ After all, RCTs are the gold standard of medical experimentation. However, such accolades only apply to welldesigned, well-executed trials. The three RCTs were neither.

The trials were nearly identical in their methodology and in the number of men in each arm of the trial who became infected. The trials shared the same biases, which led to nearly identical results. All had expectation bias (both researcher and participant), selection bias, lead-time bias, attrition bias, duration bias, and early termination that favored the treatment effect the investigators were hoping for. ${ }^{3}$ All three studies were overpowered such that the biases alone could have provided a statistically significant difference.

The common hypothesis for these trials was that male circumcision would decrease the rate of heterosexually transmitted HIV infections. A basic assumption adopted by the investigators was that all HIV infections resulted from heterosexual transmission, so no effort was made to determine the source of the infections discovered during the trial. There is strong evidence that this assumption was not valid.

In the South African trial, men who reported at least one episode of unprotected sex accounted for 2498 person-years and 46 HIV infections during the trial. Among the remaining men, who accounted for 2076 person-years, 23 become infected although they either had no sexual contact or always used a condom. These men, who had infection rate of 1.11/100 person-years $(95 \% \mathrm{CI}=0.74-1.67)$, presumably became infected through non-sexual means. The men at sexual risk of infection had an infection rate of $1.84 / 100$ person-years $(95 \% \mathrm{CI}=1.38-2.46)$. It would be expected that all men in the trial shared the same baseline risk of non-sexual transmission and any additional risk could be attributed to sexual transmission. The infections attributed to sexual contact would be the difference between the total rate and the non-sexually transmitted rate $(0.73 / 100$ person-years). Consequently, only 18 ( 0.0073 infections per person-year * 2498 person-years) of the 69 infections in the South African trial can be attributed to sexual transmission. ${ }^{4}$
Correspondence: Dr. Robert S. Van Howe, Department of Pediatrics and Human Development, College of Human Medicine, Michigan State University, 413 E. Ohio Street, Marquette, MI 49855, USA.

Tel. +1.906.2287454 - Fax: +1.906.4852726

E-mail: rsvanhowe@att.net, vanhowe@msu.edu

Key words: circumcision, HIV infection, risk compensation.

Conflict of interest: the authors report no conflicts of interest.

Received for publication: 25 October 2010 .

Accepted for publication: 9 December 2010.

This work is licensed under a Creative Commons Attribution 3.0 License (by-nc 3.0).

(C) Copyright R.S. Van Howe and M.R. Storms, 2011 Licensee PAGEPress, Italy

Journal of Public Health in Africa 2011; 2:e4 doi:10.4081/jphia.2011.e4

Similarly, in the Ugandan trial, men who consistently used condoms had the same rate of infection as those who never used condoms (Consistent condom use: 1.03/100 personyears; No condom use $0.91 / 100$ person-years; $\mathrm{RR}=1.13,95 \% \mathrm{CI}=0.54-2.38, \mathrm{P}=0.74)$. Men who reported no sexual partners for the duration of the trial accounted for 1252.1 patient-years and 6 infections $(0.48 / 100$ persons-years, $95 \% \mathrm{CI}=0.22-1.07$ ). If this rate is subtracted from the rate in sexually active men, at most 35 of the 67 infections in the Ugandan trial can be attributed to sexual transmission. ${ }^{5}$

Finally, in the first three months of the Kenyan trial, five men became HIV-positive who reported no sexual activity in the period before the seroconversion $(0.73 / 100$ personyears, $95 \% \mathrm{CI}=0.30-1.76)$. If this rate is subtracted from the overall rate of infection in the trial, at most 36 of the 69 infections in the Ugandan trial can be attributed to sexual transmission. ${ }^{6}$ Conservatively for the three trials, 89 of the 205 infections (43.1\%) were sexually transmitted. Without knowing which infections were sexually transmitted, it is impossible to test the hypothesis of whether circumcision reduces the rate of sexually transmitted HIV. Basing policy on studies that were unable to answer their own research question is unwarranted.

\section{Lack of biologic plausibility}

How does cutting off the foreskin prevent the transmission of HIV? This question remains unanswered. Proponents of the circumcision solution have speculated that the interior mucosa of the prepuce is thinner and more prone to tearing, but mucosa of the inner and outer prepuce have been shown to be of the same thickness. ${ }^{7}$ Proponents also specu- 
late that HIV is more likely to be transmitted through the foreskin because it has a high concentration of Langerhans cells, which they believe are the entry point for HIV. Research has shown that Langerhans cells are quite efficient in repelling HIV and explains why the transmission rate of HIV is one per 1000 unprotected coital acts. ${ }^{8}$ The inner foreskin secretes langerin, which kills viruses. ${ }^{9}$ Langerhans cells also protect against other sexually transmitted infections (STIs), which may explain why circumcised men are at greater risk for getting an STI (unpublished data). In general, mucosal immunity provides a stronger barrier to infection than the skin. Finally, to support their plausibility argument, circumcision proponents have identified the sub-preputial space as a harbor for sexually transmitted viruses. Meta-analyses assessing the susceptibility to genital infections with herpes simplex virus and human papilloma virus have not shown an association with circumcision status. ${ }^{10-12}$ Unfortunately, these speculations have been repeated so often in the medical literature that many physicians and public health officials consider them factual. There is, however, no direct scientific evidence to support the hypothesis that the foreskin is a predisposing factor for infection.

\section{Lack of consistent epidemiological evidence}

If the RCTs are to be believed and circumcision provides $50 \%$ to $60 \%$ protection from sexually transmitted HIV infection, then the impact of circumcision should be readily apparent in the general population. This is not the case. In Africa, there are several countries where circumcised men are more likely to be HIV infected than intact men, including Malawi, Rwanda, Cameroon, Ghana, Zimbabwe, Lesotho, Swaziland, and Tanzania. ${ }^{13-15}$ Even in South Africa, where one RCT was undertaken, $12.3 \%$ of circumcised men were HIV-positive, while $12.0 \%$ of intact men were HIV-positive. ${ }^{16}$ If the national survey data that are available from 19 countries are combined in a meta-analysis (Table 1) the random-effects model summary effect for the risk of a genitally intact man having HIV is an odds ratio of $1.10(95 \% \mathrm{CI}=0.83$ 1.46), indicating that on a general population level, circumcision has no association with risk of HIV infection. Among developed nations, the United States has the highest rate of circumcision and the highest rate of heterosexually transmitted HIV. ${ }^{17}$ Within the United States, blacks have the highest rate of circumcision ${ }^{18-21}$ and the highest rate of heterosexually transmitted HIV. ${ }^{22}$ Among English-speaking developed nations there is a significant positive association between neonatal circumcision rates and HIV prevalence (data currently under submission, Scot Anderson). On a population level, circumcision has not been found to be an effective measure and may be associated with an increase in HIV risk.

\section{Risk compensation}

Risk compensation occurs when people believe they have been provided additional protection (wearing safety belts) they will engage in higher risk behavior (driving faster). As a consequence of the increase in higher risk behavior, the number of targeted events (traffic fatalities) either remains unchanged or increases. ${ }^{23,24}$ When modeling HIV infections in San Francisco, Blower and McLean found that if an HIV-vaccine offered $50 \%$ protection, but reduced condom usage, or increased other risky behaviors, it would likely result in higher HIV infection rates. ${ }^{21}$

Risk compensation will accompany the circumcision solution in Africa. Circumcision has been promoted as a natural condom, ${ }^{25}$ and African men have reported having undergone circumcision in order not to have to continually use condoms. Such a message has been adopted by public health researchers. A recent South African study assessing determinants of demand for circumcision listed "It means that men don't have [to] use a condom" as a circumcision advantage in the materials they presented to the men they surveyed ${ }^{26}$ If circumcision results in lower condom use, the number of HIV infections will increase.

African men, on average, have coitus once a week, ${ }^{27}$ and use condoms in $48 \%$ of their sexual encounters with women. ${ }^{5}$ Assume that $20 \%$ of sexually active women are HIV-positive, partners were contacted randomly, condoms are $98 \%$ effective when used, the baseline circumcision rate is $5 \%$, and circumcision reduced the transmission rate of HIV infection by $50 \%$. Since the transmission rate of HIV from females to males is one per 1000 unprotected coital acts, the HIV infection rate in men in this scenario would be 0.537 per 100 personyears (which is far below the rate reported in the three RCTs). If the circumcision rate increases from $5 \%$ up to $75 \%$, the infection rate would decrease to 0.344 per 100 personyears. If in the baseline scenario with a $5 \%$ circumcision rate condom use increased from $48 \%$ up to $67.9 \%$ of sexual encounters, the infection rate would be 0.344 per 100 person-

Table 1. Meta-analysis of population survey results from 19 countries ${ }^{15,16}$ comparing HIV prevalence based on circumcision status using fixed-effects and random-effects models on exact odds ratios and confidence intervals. ${ }^{11}$

\begin{tabular}{|c|c|c|c|c|c|c|c|}
\hline \multirow[t]{2}{*}{ Country, year } & \multicolumn{2}{|c|}{ HIV+ve } & \multicolumn{2}{|c|}{ HIV-ve } & \multirow[t]{2}{*}{ Ex OR } & \multirow[t]{2}{*}{$95 \%$ CIL } & \multirow[t]{2}{*}{$95 \%$ CIL } \\
\hline & Intact & Cd & Intact & $\mathrm{Cd}$ & & & \\
\hline Burkina Faso, 2003 & 10 & 46 & 324 & 2685 & 1.80 & 0.80 & 3.66 \\
\hline Cambodia, 2005 & 39 & 0 & 6478 & 138 & 1.18 & 0.21 & $\infty$ \\
\hline Cameroon, 2004 & 4 & 185 & 313 & 4113 & 0.28 & 0.08 & 0.77 \\
\hline Côte d'Ivoire, 2005 & 6 & 108 & 167 & 3742 & 1.24 & 0.44 & 2.86 \\
\hline Ethiopia, 2005 & 5 & 40 & 379 & 4380 & 1.44 & 0.44 & 3.69 \\
\hline Ghana, 2003 & 3 & 54 & 178 & 3810 & 1.19 & 0.24 & 3.72 \\
\hline Guinea, 2005 & 0 & 18 & 26 & 2532 & 3.87 & $\infty$ & 23.58 \\
\hline Haiti, 2005 & 77 & 9 & 3994 & 234 & 0.50 & 0.25 & 1.15 \\
\hline India, 2005/2006 & 161 & 12 & 40184 & 5806 & 1.94 & 1.08 & 3.83 \\
\hline Kenya, 2003 & 54 & 74 & 421 & 2298 & 3.95 & 2.68 & 5.77 \\
\hline Lesotho, 2004/2005 & 161 & 223 & 885 & 728 & 0.59 & 0.47 & 0.75 \\
\hline Malawi, 2004 & 179 & 66 & 1727 & 434 & 0.68 & 0.50 & 0.94 \\
\hline Niger, 2006 & 0 & 23 & 14 & 2818 & 6.31 & $\infty$ & 39.51 \\
\hline Rwanda, 2005 & 82 & 16 & 3826 & 402 & 0.54 & 0.31 & 0.99 \\
\hline Senegal, 2005 & 0 & 16 & 56 & 3108 & 2.47 & $\infty$ & 14.81 \\
\hline South Africa, 2002 & 184 & 102 & 1485 & 814 & 0.99 & 0.26 & 1.28 \\
\hline Tanzania, 2003/2004 & 86 & 225 & 1443 & 3238 & 0.86 & 0.66 & 1.11 \\
\hline Uganda, 2004/2005 & 309 & 69 & 5304 & 1789 & 1.51 & 1.15 & 2.00 \\
\hline Zimbabwe, 2005 & 743 & 99 & 4492 & 498 & 0.83 & 0.66 & 1.06 \\
\hline Total & 2103 & 1385 & 71696 & 43567 & 0.92 & 0.86 & 0.99 \\
\hline Exact fixed effects & & & & 0.97 & 0.88 & 1.06 & \\
\hline Exact random effects & & & & 1.10 & 0.83 & 1.46 & \\
\hline \multicolumn{8}{|l|}{ Africa only } \\
\hline Exact fixed effects & & & & 0.96 & 0.87 & 1.06 & \\
\hline Exact random effects & & & & 1.10 & 0.81 & 1.50 & \\
\hline
\end{tabular}

$\mathrm{Cd}$, circumcised. Between study heterogeneity: all studies $2(\mathrm{df}=18)=113.69, \mathrm{P}<0.0001$; Africa only $2(\mathrm{df}=15)=107.22, \mathrm{P}<0.0001$. 
years. Consequently, the impact of a fifteenfold increase in the rate of circumcision could be accomplished by a relative $41 \%$ increase in the use of condoms.

\section{The leap of faith}

Interventions and medications that demonstrate efficacy in a research setting are often failures in a clinical setting. Circumcision will provide another example of this. The results from the RCTs are of questionable value, and it is unknown how they will translate to the real world. Numbers gathered from general populations are outside the $95 \%$ confidence intervals generated by the RCTs.

Research results often fail to translate to other settings because the research population differs considerably from the targeted population. For example, to save money in a trial of a new antihypertensive medication, participants with the highest blood pressure will be recruited for the trial, because it is easier to show effectiveness in those with more severe disease. The new medication may do well with the participants, but when the medication is released for general use, it may not be beneficial for those with mild hypertension, let alone those who are normotensive.

The men attracted by a free circumcision to enroll in the RCTs are not representative of the general population. The RCT participants were required to want to be circumcised. A faithful monogamous man with a faithful spouse would have little motivation to seek a free circumcision. This selection bias may have resulted in enrollment of men more likely to engage in high-risk behaviors. The free circumcision and financial inducements may have added to the selection bias.

If the selection bias resulted in more men at high risk of infection being in the trial, then the results would apply only to men who engage in high-risk behaviors. This would be consistent with the observational studies finding that the association between circumcision status and HIV infection was present primarily in studies of high-risk men.

Instead of targeting sexually active men at high risk of HIV infection, the circumcision solution proposes circumcising all males (of all ages), which would be equivalent to recommending the above antihypertensive medication to everyone regardless of their blood pressure. In addition to the national survey data (Table 1), observational studies of general populations have for the most part failed to show an association between circumcision status and HIV infection. ${ }^{28-30}$ There is no scientific reason to believe that the RCT results would necessarily apply to the general population. It is quite likely that applying research results from a high risk population to the general population will lead to failure. Using the scenario above, if it is assumed that circumcision has only a $10 \%$ protective in the general population then increasing the circumcision rate from $5 \%$ up to $75 \%$ would decrease the infection rate from 0.548 to 0.509 per 100 person-years. Increasing condom use from $48 \%$ up to $51.8 \%$ would result in the same gains. So a fifteenfold increase in the circumcision rate would have the same impact as a $3.8 \%$ absolute increase in the use in condoms.

\section{Attractive, less invasive, less expensive, more effective alternatives}

Before Africans address sexually transmitted HIV, a concerted effort to eliminate the iatrogenic spread of the virus is needed. As the numbers from the RCTs indicate, most infections can be attributed to non-sexual transmission. While this indictment of the medical system is unsettling, ignoring iatrogenic sources of infection will only allow the African epidemic to flourish. ${ }^{31}$

When it comes to sexually transmitted HIV infections, proponents of circumcision have consistently failed to compare the effectiveness and cost of circumcision to currently available alternatives, which include condoms, aggressive surveillance and treatment of STIs, and antiretroviral therapy (ART).

ART is a secondary preventive measure. When those infected with HIV are treated with ART, the viral counts can decrease to where the patient is no longer contagious. HIV-infected patients on ART with no currently active STI no longer need to use condoms to protect their partners. $^{32} \mathrm{~A}$ recent model predicted that a "test and treat" model in a sub-Saharan setting could reduce the number of new HIV infections by $55-73.2 \%,{ }^{33}$ making this approach attractive in Africa, San Francisco, and Washington, DC. ${ }^{34}$ This intervention directs prevention at those most likely to benefit: those exposed to the virus. With the circumcision solution, the vast majority of men who are circumcised will not benefit from the procedure (Figure 1). Secondary prevention is a more efficient use of resources and many HIV experts consider primary prevention extremely wasteful and ineffective. ${ }^{8}$ The "test and treat" approach is effective regardless of whether the infection was sexually or iatrogenically transmitted. Such an approach would not be limited to ART, as the use of other medications proven to decrease viral counts, such as decitabine and gemcitabine, may also become available. ${ }^{35}$

Aggressive surveillance and treatment of STIs has been shown to reduce the number of HIV infections by $40 \%{ }^{36}$ at a cost of $\$ 217.62$ per HIV-1 infection averted. ${ }^{37}$ This is more costeffective than models for circumcision, which extrapolate the data collected from the 21 to 24 months of the RCTs to over 20 years, have predicted. These models, which incorporated major assumptions of questionable validity,

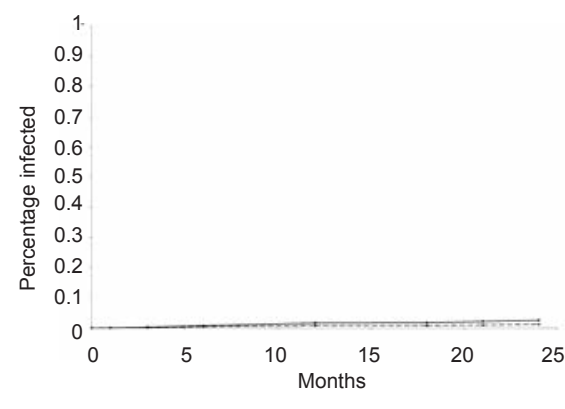

Figure 1. Cumulative HIV infections over time using the combined data from three randomized clinical trials with early circumcision represented with the solid line and delayed circumcision (control group) in the dashed line. Nearly all of the men in the trial remained infection free.

presented circumcision as favorably as possible. In addition to being more cost-effective, aggressive surveillance and treatment of STIs have the advantage of treating and preventing the spread of STIs and avoiding the damage caused by removing the most sensitive portion of penis. ${ }^{38}$ Part of the success of STI treatment research may be due to a reduction of iatrogenically transmitted HIV, as the STIs were treated in research facilities.

In studies of discordant couples, condoms have been shown to be more than $99 \%$ effective in preventing infection. ${ }^{39}$ Condoms, in a public health setting, cost $2.5 \mathrm{c}$ each. ${ }^{40} \mathrm{~A}$ safe circumcision performed under sterile conditions in Africa using local anesthetic costs approximately $\$ 75,{ }^{41}$ so for the cost of an adult circumcision, 3000 condoms, at $2.5 \mathrm{C}$ per condom, can be purchased. The nearly complete protection provided by condoms is a bargain compared with circumcision. In the first hypothetical scenario outlined above, the 0.193 infections per 100 person-years decrease in HIV infection rate brought by circumcision costs $\$ 52.50$ per person. The cost per person of the additional condoms (at 2.5c each) for one year to achieve the same impact on the infection rate would total $25.87 \mathrm{c}$. To have the same effect for one year, circumcision costs 202.9 times more than condoms. Proponents for circumcision would argue that circumcision is a one-time expenditure, while condoms would be an ongoing expense. Using the scenario above with $3 \%$ discounting and assuming an average of weekly sexual contact over 45 years, the lifetime difference in the cost of condoms would be $\$ 6.13$ per person. With 5\% discounting the lifetime difference in cost would be $\$ 4.83$. If circumcision is only $10 \%$ effective, with a $3 \%$ discount, the lifetime difference in cost of condoms would be $\$ 1.25$.

One complaint has been that the $2.5 \mathrm{c}$ condoms are not attractive, which may explain why they are underused. Based on this analysis, if a man is having sex weekly for 45 years, an upgrade to condoms that cost ten times as 
much would be cost neutral (assuming a discount rate of $3 \%$ ). Of course, if sexual contact was less frequent or a man was in a mutual monogamous relationship, further condom upgrades could be justified.

This is, however, a false comparison because, unlike circumcision, condoms can provide nearly complete protection.

Circumcision proponents believe that circumcision is the only proven effective preventive tool for HIV infection and have argued that condoms are ineffective. ${ }^{42,43}$ Condoms would be expected to be ineffective in regions where the majority of infections are from non-sexual transmission. Abstinence, be faithful, and condoms (ABC) should remain the focus of primary prevention for sexually transmitted HIV, but more resources need to be focused on the non-sexually transmitted infections, which is a much more efficient means of transmission. ${ }^{31}$

How rational is it to tell men that they must be circumcised to prevent HIV, but after circumcision they still need to use a condom to be protected from sexually transmitted HIV? Condoms provide near complete protection, so why would additional protection be needed? It is not hard to see that circumcision is either inadequate (otherwise there would be no need for the continued use of condoms) or redundant (as condoms provide nearly complete protection). The argument that men don't want to use condoms needs to be addressed with more attractive condom options and further education that sex without a condom and without a foreskin is potentially fatal, while sex with a condom and a foreskin is safe. No nuance is needed. Offering less effective alternatives can only lead to higher rates of infection.

Rather than wasting resources on circumcision, which is less effective, more expensive, and more invasive, focusing on iatrogenic sources and secondary prevention should be the priority, since it provides the most impact for the resources expended. The second tier would be primary prevention that focuses on the ABCs.

Resources are not unlimited. With the push for circumcision, public health workers in Africa are finding that resources that previously paid for condoms are now being redirected to circumcision. With every circumcision performed, 3000 condoms will not be available. For every circumcision performed, a health care provider is prevented from caring for someone in need of medical care. With trained medical providers busy performing circumcisions, patients will be forced to seek medical care provided in settings where sterility of equipment is less likely and HIV is more likely to be spread iatrogenically. For every circumcision performed, there are fewer resources that can be put into ART and other chemotherapies. Male circumcision is an unnecessary distraction that depletes the limited resources avail- able to address the HIV epidemic. It also fails to address the underlying causes for the epidemic in Africa.

\section{References}

1. World Health Organization, UNAIDS. Male circumcision: global trends and determinants of prevalence, safety and acceptability. 2007. Available at: http://www.malecircumcision.org/media/documents/MC_Glob al_Trends_Determinants.pdf

2. World Health Organization, UNAIDS. New data on male circumcision and HIV prevention: policy and programme implications. 2007. Available at: http://www. unaids.org/en/media/unaids/contentassets/dataimport/pub/report/2007/mc_recommendations_en.pdf

3. Halperin DT, Bailey RC. Male circumcision and HIV infection: 10 years and counting. Lancet 1999; 354:1813-5.

4. Auvert B, Taljaard D, Lagarde E, et al. Randomized, controlled intervention trial of male circumcision for reduction of HIV infection risk: The ANRS 1265 Trial. PLoS Med 2005;2:e298.

5. Gray RH, Kigozi G, Serwadda D, et al. Male circumcision for HIV prevention in men in Rakai, Uganda: a randomised trial. Lancet 2007;369:657-66.

6. Bailey RC, Moses S, Parker CB, et al. Male circumcision for HIV prevention in young men in Kisumu, Kenya: a randomised controlled trial. Lancet 2007;369:643-56.

7. Dinh MH, McRaven MD, Kelley Z, et al. Keratinization of the adult male foreskin and implications for male circumcision. AIDS 2010;24:899-906.

8. Chin J. The AIDS pandemic: the collision of epidemiology with political correctness. 2007. Radcliffe Publ., Abingdon, OX,UK

9. de Witte L, Nabatov A, Pion M, , et al. Langerin as a natural barrier to HIV-1 transmission by Langerhans cells. Nat Med 2007;13:367-71.

10. Weiss HA, Thomas SL, Munabi SK, Hayes RJ. Male circumcision and risk of syphilis, chancroid, and genital herpes: a systematic review and meta-analysis. Sex Transm Infect 2006;82:101-10.

11. Van Howe RS. Human papillomavirus and circumcision: A meta-analysis. J Infect 2007;54:490-6.

12. Van Howe RS, Storms MR. Circumcision to prevent HPV infection. Lancet Oncol 2009;10:746-7.

13. Garenne M. Long-term population effect of male circumcision in generalised HIV epidemics in sub-Saharan Africa. Afr J AIDS Res 2008;7:1-8.

14. Demographic and Health Surveys. HIV
Prevalence and Associated Factors (Chapter 15). In: Rwanda National Health and Demographic Survey for 2005. Available at: http://www.measuredhs.com/ pubs/pdf/FR183/15Chapter15.pdf

15. Mishra V, Medley A, Hong Ret al. Levels and Spread of HIV Seroprevalence and Associated Factors: Evidence from National Household Surveys. 2009. DHS Comparative Reports No. 22. Macro International Inc., Calverton, MD, USA.

16. Connolly C, Shanmugam R, Simbayi LC, Nqeketo A. Male circumcision and its relationship to HIV infection in South Africa: Results of a national survey in 2002. S Afr Med J 2008;98:789-94.

17. UNAIDS, World Health Organization. Global HIV/AIDS and STD Surveillance Project: Report on the global HIV/AIDS epidemic 1998. Available at: http://www. unaids.org/hivaidsinfo/statistics/june98/gl obal_report/index.html.

18. O'Brien TR, Calle EE, Poole WK. Incidence of neonatal circumcision in Atlanta, 19851986. South Med J 1995;88:411-5.

19. Xu F, Markowitz LE, Sternberg MR, Aral SO. Prevalence of circumcision and herpes simplex type 2 infection in men in the United States: the National Health and Nutrition Examination Survey (NHANES), 1999-2004. Sex Transm Dis 2007;34:47984.

20. Mor Z, Kent CK, Kohn RP, Klausner JD. Declining rates in male circumcision amidst increasing evidence of its public health benefit. PLoS ONE 2007;2:e861.

21. Mansfield CJ, Hueston WJ, Rudy M. Neonatal circumcision: associated factors and length of hospital stay. J Fam Pract 1995;41:370-6.

22. US Centers for Disease Control and Prevention. Racial/ethnic disparities in diagnoses of HIV/AIDS - 33 states, 20012005. MMWR Morb Mort Wkly Rep 2007;56:189-93.

23. Blower SM, McLean AR. Prophylactic vaccines, risk behaviour change, and the probability of eradicating HIV in San Francisco. Science 1994;265:1451-4.

24. Richens J, Imrie J, Copas A. Condoms and seat belts: the parallels and the lessons. Lancet 2000;355:400-3.

25. Bonner K. Male circumcision as an HIV control strategy: not a 'natural condom'. Reprod Health Matters 2001;9:143-55.

26. Bridges JFP, Selck FW, Gray GE, et al. Condom avoidance and determinants of demand for male circumcision in Johannesburg, South Africa. Health Policy Planning 2010; e-pub ahead of print.

27. Sawers L, Stillwaggon E. Concurrent sexual partnerships do not explain the HIV epidemics in Africa: a systematic review of the evidence. J Int AIDS Soc 2010; 13: 34. 
28. Grosskurth H, Mosha F, Todd J, et al. A community trial of the impact of improved sexually transmitted disease treatment on the HIV epidemic in rural Tanzania: 2. Baseline survey results. AIDS 1995;9:92734.

29. O'Farrell N, Egger M. Circumcision in men and the prevention of HIV infection: a "meta-analysis" revisited. Int J STD AIDS 2000;11: 137-42.

30. Van Howe RS. Circumcision and HIV infection: review of the literature and metaanalysis. Int J STD AIDS 1999;10:8-16.

31. Gisselquist D. Points to consider: responses to HIV/AIDS in Africa, Asia and Caribbean. 2008. Adonis \& Abbey Publ. Ltd, London, UK.

32. Vernazza P. La prévention du sida devient plus simpl, mais aussi plus complexe! Bull Med Suisses 2008;89:163-4.

33. Bendavid E, Brandeau ML, Wood R, Owens DK. Comparative effectiveness of HIV test- ing and treatment in highly endemic regions. Arch Int Med 2010;170:1357-54.

34. Charlebois ED, Havlir DV. "A Bird in the Hand...": a commentary on the test and treat approach for HIV. Arch Int Med 2010;170:1354-6.

35. Clouser CL, Patterson SE, Mansky LM. Exploiting drug repositioning for discovery of a novel HIV combination therapy. J Virol 2010;84:9301-9.

36 Grosskurth H, Mosha F, Todd J, et al. Impact of improved treatment of sexually transmitted diseases on HIV infection in rural Tanzania: randomised controlled trial. Lancet 1995;346:530-6.

37. Gilson L, Mkanje R, Grosskurth H, et al. Cost-effectiveness of improved treatment services for sexually transmitted diseases in preventing HIV-1 infection in Mwanza Region, Tanzania. Lancet 1997;350:1805-9.

38. Sorrells ML, Snyder JL, Reiss MD, et al. Fine-touch pressure thresholds in the adult penis. BJU Int 2007;99:864-9.

39. de Vincenzi I. A longitudinal study of human immunodeficiency virus transmission by heterosexual partners. European Study Group on Heterosexual Transmission of HIV. N Engl J Med 1994;331:341-6.

40. Shelton JD, Johnston B. Condom gap in Africa: evidence from donor agencies and key informants. Br Med J 2001;323:139.

41. Krieger JN, Bailey RC, Opeya J, et al. Adult male circumcision: results of a standardized procedure in Kisumu District, Kenya. BJU Int 2005;96:1109-13.

42. Potts M, Halperin DT, Kirby D, et al. Reassessing HIV prevention. Science 2008;320:749-50.

43. Klausner JD, Wamai RG, Bowa K, et al. Is male circumcision as good as the HIV vaccine we've been waiting for? Future HIV Ther 2008;2:1-7. 